\title{
Avaliação da citotoxicidade e da genotoxicidade do antisséptico bucal gluconato de clorexidina $0,12 \%$ em células meristemáticas de raízes de
} Allium cepa

Eduardo Lopes Carreito de Alencar

Ítalo Araújo Rios Brandão

Jackson de Sá Sousa

Tássyo Alax Nascimento Sampaio de Oliveira

Talvany Luís de Barros

Rosemarie Brandim Marques

Débora de Alencar Franco Costa

\section{Registro DOI: http://dx.doi.org/10.22280/revintervol12ed2.442}

\begin{abstract}
Resumo
O objetivo deste trabalho foi verificar o efeito citotóxico e genotóxico do antisséptico bucal gluconato de clorexidina por meio do teste de Allium cepa. As soluções utilizadas foram $0,03 \%$, $0,06 \%$ e $0,12 \%$, além do controle positivo e negativo. Observou-se 1.000 células por tratamento. Os efeitos citotóxicos e genotóxicos foram avaliados pelo índice mitótico e aberrações cromossômicas e os dados submetidos à comparação por meio do teste ANOVA considerando I.C. 95\% 3p < 0,05. Os resultados evidenciaram um decréscimo no índice mitótico nas células meristemáticas das cebolas submetidas às soluções de gluconato de clorexidina em todas as concentrações, diferindo-se estatisticamente do controle. Em todas as concentrações aconteceram alterações numéricas referentes às aberrações cromossômicas e presença de micronúcleos. Contudo, estatisticamente não houve significância no que se refere à citotoxicidade, evidenciando-se apenas significância nos parâmetros genotóxicos sobre as raízes de $A$. cepa.
\end{abstract}

Palavras-chave: Micronúcleos. Índice mitótico. Clorexidina.

Evalution of cytotoxicity and genotoxicity of antiseptic mouth chlorhexidine gluconate $\mathbf{0 , 1 2 \%}$ in meristematic cells of Allium cepa roots

\begin{abstract}
The objective of this work was to verify the cytotoxic and genotoxic effect of oral antiseptic chlorhexidine gluconate by means of the Allium cepa test. The solutions used were $0.03 \%$, $0.06 \%$ and $0.12 \%$, in addition to the positive and negative controls. 1000 cells were observed per treatment. The cytotoxic and genotoxic effects were evaluated by mitotic index and Revinter, v. 12, n. 02, p. 05-13, jun. 2019.




\section{Revinter}

chromosomal aberrations and the data submitted to the comparison using the ANOVA test considering $\mathrm{p}<0.05$. The results evidenced a decrease in the mitotic index in the meristematic cells of the onions submitted to chlorhexidine gluconate solutions at all concentrations, differing statistically from the control. In all concentrations, there were numerical changes regarding chromosomal aberrations and the presence of micronuclei. However, there was no statistically significant cytotoxicity, evidencing only the significance ingenotoxic parameterson the roots of A. cepa.

Key-words: Micronucleus. Mitotic Index. Chlorhexidine.

Recebido em 13/05/2019 Aceito em 07/06/2019

\section{INTRODUÇÃO}

O câncer bucal é considerado um problema de saúde pública em todo o mundo. A última estimativa mundial apontou que ocorreriam cerca de 300 mil casos novos e 145 mil óbitos, para o ano de 2012, por câncer de boca e lábio (INCA, 2014).

Embora as neoplasias malignas possam ter origem em todos os tecidos que compõem a boca, aproximadamente $94 \%$ de todas as malignidades da boca são oriundas do tecido epitelial de revestimento por sua maior exposição à ação de agentes potencialmente carcinogênicos por meio de inalação, ingestão ou bochecho (FENECH, 2000; INCA, 2014).

Alguns tipos de câncer podem ser prevenidos pela eliminação da exposição aos fatores de risco como fumo, álcool, medicamentos, mate e alimentos (DIETZ, et al., 2000).

A clorexidina é uma bis-guanidina que possui propriedades hidrofílicas e hidrofóbicas. Geralmente é utilizada na forma de sal de gluconato. O gluconato de clorexidina é uma droga amplamente utilizada em protocolos médicos e odontológicos (MUÑOZ-SOLARTE; GUERRERO-PEPINOSA, 2013), principalmente na odontologia como enxaguante bucal nas áreas de periodontia, cirurgia e implantodontia (LABBATE et al., 2003).

Antissépticos a base de clorexidina são utilizados em odontologia há muitos anos como padrão-ouro no controle químico da placa bacteriana. A ação dessa substância também tem sido preconizada em protocolos de diversos campos da medicina, sendo eles invasivos ou não, e até mesmo em áreas consideradas delicadas e/ou de difícil manipulação, e seu bom desempenho bactericida e bacteriostático é comprovado através de diversos estudos, principalmente pelas 


\section{Revinter}

suas propriedades de amplo espectro de ação, substantividade, seu fácil acesso e baixo custo, atribuindo à clorexidina uma abordagem mais criteriosa (AMORAS, 2013).

Os colutórios a base de gluconato de clorexidina têm sido alvos de diversos estudos epidemiológicos de câncer bucal. Entretanto, o potencial genotóxico do gluconato de clorexidina a 0,12\% ainda não foi esclarecido (DANTAS et al., 2010).

Silva et al. (2012) avaliaram a mucosa oral de 30 indivíduos que realizaram bochecho com o gluconato de clorexidina a $0,12 \%$ e os resultados deste estudo mostraram que a clorexidina a $0,12 \%$ induz mutagenicidade e citotoxidade, e pode ocasionar apoptose tanto por fragmentação como também por dissolução nuclear.

Allium cepa (cebola) é um vegetal superior muito utilizado por pesquisadores em ensaios toxicológicos por meio da avaliação de parâmetros macroscópicos como alteração de cor, formato, tamanho da raiz e deformidade e ainda microscópicos como aberrações cromossômicas e micronúcleos (LONGHIN, 2008).

A grande vantagem do uso de plantas superiores sobre os outros sistemas se dá, sobretudo, pelo fato de seus cromossomos serem grandes e das plantas responderem aos mutágenos de maneira similar aos mamíferos e outros eucariotos (FREYRE, ESTRADA, BOLAÑOS, 2009). Especificamente para Allium cepa, a vantagem encontra-se em ser uma espécie com pequeno número de cromossomos $(n=8)$, ter um ciclo celular relativamente curto e controlável em condições estáveis (de cerca de 14 horas a $25^{\circ} \mathrm{C}$ ), envolver um método barato, rápido, de fácil manuseio e o ano inteiro (FISKEJO, 1985; TEDESCO; LAUGHINGHOUSE IV, 2012) e sobretudo, por fornecer boa concordância com outros bioensaios de genotoxicidade (MATSUMOTO et al., 2006). Consequentemente, resultados positivos no teste de Allium cepa devem ser considerados como um alerta e também um indicativo de que o fator químico testado pode ser um risco para a saúde do homem (FISKESJÖ, 1985).

Com intuito de proteger a saúde de pacientes que usam de forma prolongada os colutórios à base de clorexidinaa $0,12 \%$, o presente trabalho teve como objetivo estudar por meio do teste Allium cepa os possíveis efeitos citotóxicos e genotóxicos do enxaguante bucal à base de gluconato de clorexidina em diferentes concentrações, investigando o índice mitótico (citotoxicidade) e a frequência de aberrações cromossômicas e de micronúcleos (genotoxicidade) que podem causar instabilidade no material genético podendo levar ao aparecimento de neoplasias malignas. 


\section{MATERIAIS E MÉTODOS}

\section{Revinter}

\section{Aspectos Éticos}

Como o presente estudo foi realizado em vegetais não foi necessário o encaminhamento desta pesquisa para a aprovação do Comitê de Ética e Pesquisa da FACID/DeVry.

\section{Delineamento e amostra do estudo}

Tratou-se de um estudo experimental e comparativo. A pesquisa foi realizada no Laboratório Multidisciplinar na sede da Faculdade Integral Diferencial-FACID/DEVRY na Rua Veterinário Bugyja Brito, No 1354, Bairro Horto Florestal, em Teresina-PI.

Foram utilizados 04 frascos de $250 \mathrm{~mL}$ do colutório de gluconato de clorexidina $0,12 \%$ sem álcool (Periogard®), diluídos e divididos em três concentrações diferentes $(0,03 \%, 0,06 \%$ e $0,12 \% \mathrm{mg} / \mathrm{L}$ ), e 25 cebolas (Allium cepa) para realizar o teste citotóxico e genotóxico, colocando 5 cebolas para cada concentração, 5 cebolas para o grupo controle negativo com água sem cloro e 5 cebolas para o grupo controle positivo com solução de sulfato de cobre $0,03 \%$.

\section{Teste Allium cepa}

Este trabalho seguiu o protocolo sugerido pela Sociedade Brasileira de Mutagênese Carcinogênese e Teratogênese Ambiental (SBMCTA) elaborado por Medeiros et al. (2007).

Para cada concentração 05 bulbos foram colocados em contato com água sem cloro por 70 horas e nas soluções testes por 2 horas, como estabelecido no protocolo para substâncias químicas, além de controle negativo com água sem cloro e controle positivo utilizando a solução de sulfato de cobre $0,03 \%$. Após 72 horas as raízes foram medidas com o auxílio de régua e cortadas. Os critérios de inclusão foram: bulbos com raízes de aproximadamente 1 a 2 $\mathrm{cm}$. E os critérios de exclusão definem-se por: raízes de $01 \mathrm{~cm}$ e maiores que $2 \mathrm{~cm}$, bem como aquelas deformadas. Logo após, houve exposição à solução fixadora-Carnoy (etanol/ácido acético - 3:1) por 24 horas. Em seguida, as raízes foram retiradas do fixador, colocadas em etanol 70\% e mantidas na geladeira para conservação até o momento da preparação histológica das lâminas. Para o preparo das lâminas, selecionaram-se duas a três pontas de raízes retiradas do etanol $70 \%$ e colocadas sobre uma Placa de Petri, em seguida as raízes passaram por três lavagens com água destilada de 5 minutos cada; por uma lavagem com ácido clorídrico $(\mathrm{HCl})$ $1 \mathrm{~N}$ por 11 minutos e novamente por uma lavagem com água destilada, depois as raízes foram 


\section{Revinter}

coradas com Reativo de Schiff por 2 horas. As raízes foram colocadas sobre uma lâmina onde a região meristemática foi separada, logo em seguida adicionou-se sobre os materiais seccionados, uma gota de carmim acético $2 \%$ e cobrindo com lamínulas pressionando para que as células ficassem bem dispostas facilitando a visualização ao microscópio. Imediatamente após a confecção, as lâminas foram analisadas ao microscópio ótico, mil células para cada lâmina, totalizando 5 mil células por concentração.

O preparado levado ao microscópio para observação foi fotografado para melhor e mais eficiente leitura.

\section{ANÁLISE DE DADOS}

A análise mutagênica constou da determinação do índice mitótico (citotoxicidade), da frequência de aberrações cromossômicas (AC) e de micronúcleos (genotoxicidade) em 1000 células por lâmina.

O Índice Mitótico (IM), que corresponde à relação do número de células em divisão e total de células observadas, em porcentagem, analisou a presença de metáfase, anáfase e telófase. Para contagem de AC quantificaram-se as seguintes anormalidades de anáfasetelófase: Ponte, cromossomos retardatários, e quebra cromossômica, sendo todos os registros reunidos em uma só categoria para possibilitar a avaliação das AC como um único "endpoint".

O teste dos micronúcleos foi realizado comparando o número de micronúcleos dos grupos com diferentes concentrações de gluconato de clorexidina com os do grupo controle.

Para a comparação entre os resultados do grupo controle e das diferentes concentrações das substâncias teste, foi utilizado o teste ANOVA considerando Intervalo de Confiança de $95 \%$ e $\mathrm{p}<0,05$.

\section{RESULTADOS E DISCUSSÃO}

O gluconato de clorexidina é amplamente utilizado na saúde bucal como controlador da placa bacteriana e com potencial bactericida e bacteriostático. No entanto, o mesmo princípio ativo capaz de melhorar aspectos específicos da saúde, também pode interagir no organismo, levando à instabilidade genética em virtude de danos agregados ou não no DNA. 


\section{Revinter}

O resultado da citotoxicidade e genotoxicidade do gluconato de clorexidina pelo teste Allium cepa esta apresentado na Tabela 1. A citotoxicidade, através da inibição da divisão celular, em meristemas de raízes de Allium cepa, foi observada, após exposição ao gluconato de clorexidina, mostrada pela inibição do índice mitótico. Na maior concentração, a inibição foi acima de $62 \%$, em relação ao controle negativo. Apesar da maior inibição observada para a concentração de $0,12 \%$, não ocorreu significância entre as concentrações, como se observa em relação ao valor de p na Tabela 1 .

Tabela1 - Mutagenicidade do gluconato de clorexidina em de raízes de Allium cepa, avaliada através da presença de MN, AC e Índice mitótico no sistema Allium cepa

Teresina, 2017

\section{TRATAMENTO}

\begin{tabular}{|c|c|c|c|c|c|}
\hline \multirow[t]{2}{*}{ ÍNDICES } & Controle & Clorexidina & Clorexidina & Clorexidina & Controle \\
\hline & negativo & $0.03 \%$ & $0,06 \%$ & $0,12 \%$ & Positivo \\
\hline
\end{tabular}

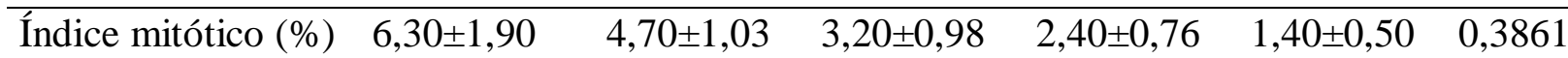

Índice de AC $(\%) \quad 3,10 \pm 1,00 \quad 2,76 \pm 0,99 \quad 25,00 \pm 0,53 \quad 33,33 \pm 0,88 \quad 50,00 \pm 5,01 \quad<0,001 * * *$

Índice de frequência

de $\mathrm{MN}(\%)$

$0,3 \pm 0,01 \quad 0,30 \pm 0,04 \quad 0,80 \pm 0,02 \quad 0,90 \pm 0,00 \quad 2,50 \pm 1,98 \quad 0,4920$

Legenda: MN, micronúcleos; AC, aberrações cromossômicas; p para ANOVA, com Intervalo de Confiança em 95\% e significância em $\mathrm{p}<0,05$.

A avaliação da mutagenicidade, obtida pela frequência de micronúcleos no gluconato de clorexidina, exposto a diferentes concentrações. A frequência de micronúcleos não apresentou significância estatística em nenhuma concentração, apesar de ter manifestado variações numéricas (Tabela 1).

Para Salvadori et al., (2008), a presença de micronúcleos, apesar de ser um processo natural e orgânico, podem funcionar como indicadores de mutagenicidade, pois quando há 
aumento do número de micronúcleos após exposição a agentes mutagênicos, os mesmos funcionam como marcadores biológicos de danos genéticos.

O perfil fotomicrográfico de micronúcleos e aberrações cromossômicas nas concentrações $0,03 \%, 0,06 \%$ e $0,12 \%$ do gluconato de clorexidina exposto ao Allium cepa está apresentado na Figura 01.

\section{Figura 1 - Perfil fotomicrográfico de micronúcleos e aberrações cromossômicas}
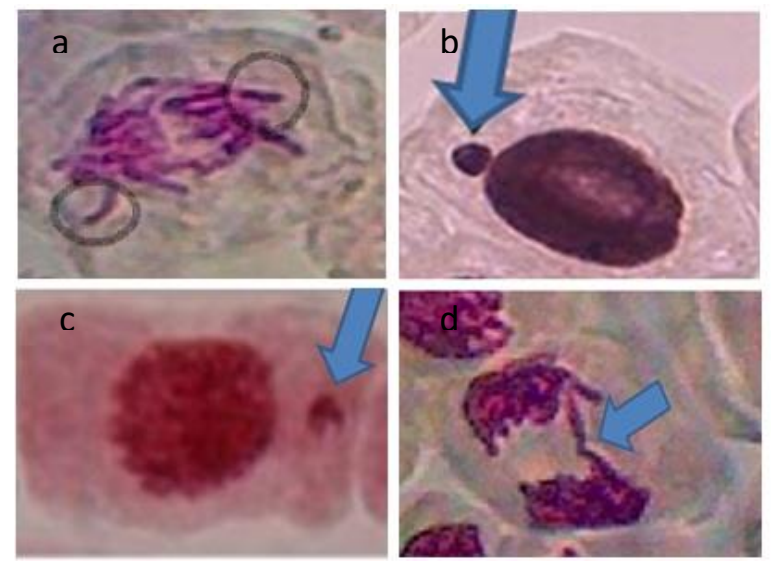

Legenda: b/c - micronúcleo; d-aberração cromossômica

No aspecto das aberrações cromossômicas houve significância do grupo controle negativo em relação ao grupo controle positivo $(\mathrm{p}<0,001)$, e também nas concentrações de clorexidina $0,03 \%(\mathrm{p}<0,0151), 0,06 \%(\mathrm{p}<0,001)$ e $0,12 \%(\mathrm{p}<0,001)$, como se pode observar na Tabela 1.

Dados esses que, de forma similar, foram encontrados por Silva et al. (2012), o qual identificou danos à mucosa oral de 30 indivíduos que realizaram bochecho com gluconato de clorexidina $0,12 \%$, constatando o aumento do risco de mutagenicidade e genotoxicidade provocada pela substância em estudo.

\section{CONCLUSÃO}

Em síntese, o presente estudo evidenciou que o gluconato de clorexidina, nas concentrações testadas, pode sim apresentar atividades citotóxicas e mutagênicas, pela 
frequência de micronúcleos e de aberrações cromossômicas em meristemas de raízes de Allium cepa, devido a efeitos clastogênicos e aneugênicos.

Assim, diante dos resultados apresentados, sugere-se mais cautela para o uso indiscriminado do gluconato de clorexidina, em benefício da saúde pública da população, bem como, para a prevenção de instabilidades genéticas e desenvolvimento do câncer.

\section{REFERÊNCIAS BIBLIOGRÁFICAS}

AMORAS, L. S.. Uso da clorexidina na Medicina: Revisão de Literatura. 2013. 36 f. Monografia (Especialização em Endodontia)- Faculdade de Odontologia de Piracicaba, Universidade Estadual de Campinas, Piracicaba, 2013.

DANTAS, S.M.M.M. et al. Mutagenicidade do gluconato de clorexidina em células esfoliadas da mucosa oral. In: $56^{\circ}$ Congresso Brasileiro de Genética, 2010, Guarujá. Anais eletrônicos. Guarujá: Sociedade Brasileira de Genética, 2010. Disponível em :< http://web2.sbg.org.br/congress/sbg2008/pdfs2010/MU059-33022.pdf>. Acesso em : 27out.2015.

DIETZ, J. et al. Pesquisa de micronúcleos na mucosa esofágica e sua relação com fatores de risco ao câncer de esôfago.RevAssMed Brasil, v. 46(3), p. 207-211, 2000.

FENECH, M.; The in vitro micronucleus technique. Mutation Research, v.455, p.8195,2000 .

FISKESJÖ, G. The Allium test: a standard in environmental monitoring. Hereditas, v.102, p.99-112, 1985.

FREYRE, S., ESTRADA, M., BOLAÑOS, H. Estudio preliminar de lacitotoxicidad y lagenotoxicidad de unextracto de origen vegetal conocido como palmo rosado en células meristemáticas de Allium cepa. Revista Memorias, v.5(12), p.12-17, 2009.

INSTITUTO NACIONAL DO CANCER. Estimativa da incidência e mortalidade por câncer no Brasil. Disponível em: <http://www.inca.gov.br/estimativa2014/>. Acesso em: 26. out.2015. 
LABBATE, R.; LEHN, C. N.; DENARDIN, O. V. P. Efeito da clorexidina na mucosite induzida por radioterapia em câncer de cabeça e pescoço. Rev. Bras. Otorrinolaringol.,v. 69(3), p. 349-54.2003.

LONGHIN, S. R. Estudo da degradação dos antibióticos beta-lactâmicos amoxicilina e ampicilina e avaliação da toxicidade e biodegradabilidade dos seus produtos. Tese ( Doutorado em Química) -Universidade de Brasília, 2008.

MEDEIROS, R. M. T. et al .Teratogenicityof Mimosa tenuiflora seedstopregnantrats. Toxicons, v. 51,p.316-319, 2007.

MUÑOZ-SOLARTE, D. M.; GUERRERO-PEPINOSA, N.. Allium test para evaluar el efecto citotóxico y genotóxico de extractosnaturalesen células meristeméticas de Allium cepa.

Memorias, v. 11(19), p. 83-86, 2013.

SALVADORI, D. M. F. et al. Effect of beta-carotene on clastogenic effects of mitomycin C, methyl methanesulfonate and bleomycin in $\mathrm{CHO}$ cells.Mutagenesis. London, v. 9, n. 1, p. 5357, jan. 2008.

SILVA, T. C..et al. Efeitos genotóxicos do gluconato de clorexidina a $\mathbf{0 , 1 2 \%}$ em epitélio de mucosa oral. Iniciação científica-UFPI, 2012, Teresina. Disponível em: < http://www.ufpi.br/21sic/Documentos/RESUMOS/Modalidade/Vida/Thaise\%20Cardoso.pdf> . Acessoem : 27out.2015.

TEDESCO, S. B.; LAUGHINGHOUSE IV, H. D. (2012).Bioindicator of Genotoxicity: The Allium cepa Test, Environmental Contamination,Dr. Jatin Srivastava. Disponível em: <http://cdn.intechopen.com/pdfs/29315/InTechBioindicator_of_genotoxicity_the_allium_cep a_test.pdf>.Acesso em: 26.out. 2015. 